\title{
As Concepções Gramscianas de Educação e de Escola Unitária nas Publicações Brasileiras ${ }^{1}$
}

\section{Gramscian Conceptions of Education and Unitary School in Brazilian Publications}

\section{Priscila Meier de Andrade Tribeck \\ Danuta Estrufika Cantóia Luiz* Aldimara Catarina Brito Delabona Boutin ${ }^{* *}$}

\begin{abstract}
Resumo: $O$ artigo aqui apresentado é fruto de uma pesquisa desenvolvida pelo Núcleo de Estudos e Pesquisa: Estado Políticas Públicas e Práticas Sociais (NUPPS). Tem como objetivo traçar uma análise das concepções de Educação, Escola Unitária e Escola Desinteressada no conjunto de artigos gramscianos disponíveis no IGS- Brasil. Também é objetivo do mesmo, apresentar em que medida as concepções de educação dispostas no conjunto dos artigos se aproximam ou se distanciam das reflexões teóricas de Gramsci. Como metodologia recorreu-se: a) levantamento dos artigos que tratam da categoria educação no IGS - Brasil; b) identificação das temáticas que se destacam junto a categoria educação; c) seleção dos fragmentos mais significativos; d) análise dos fragmentos a luz do referencial gramsciano. Conclui-se que as categorias Escola unitária e Educação desinteressada se destacam nos artigos que tem como objetivo discutir sobre educação na perspectiva gramsciana e que as concepções postas pelos mesmos se alinham a proposta de educação e escola apresentada no conjunto da obra de Antônio Gramsci.
\end{abstract}

Palavras-chave: Mapa Bibliográfico de Gramsci no Brasil; Concepção de Educação; Concepção de Escola Unitária e Desinteressada.

\footnotetext{
${ }^{1}$ Uma versão preliminar deste texto foi apresentada no "III SIMPÓSIO INTERNACIONAL INTERDISCIPLINAR EM CIÊNCIAS SOCIAIS APLICADAS: Democracia e direitos humanos” realizado em Ponta Grossa- PR, entre 11 a 13 de setembro de 2019, sendo indicado pelo evento para compor este volume especial da Emancipação.

* Doutoranda em Ciências Sociais Aplicadas pela Universidade Estadual de Ponta Grossa. Mestre em Ensino de Ciência e Tecnologia pela UTFPR. Graduada em Pedagogia e Administração Pública pela Universidade Estadual de Ponta Grossa. Professora Assistente da Universidade Tecnológica Federal do Paraná. E-mail: pmtribeck@utfpr.edu.br.

** Doutora e Mestre em Serviço Social pela Pontifícia Universidade Católica de São Paulo. Graduada em Serviço Social pela UEPG e Professora do Programa de Pós-Graduação em Ciências Sociais Aplicadas e Bacharelado em Serviço Social da Universidade Estadual de Ponta Grossa. E-mail: danutaluiz88@gmail.com.

*** Doutoranda em Educação pela Universidade Estadual de Ponta Grossa, Mestre em Educação pela Universidade Estadual de Ponta Grossa, Graduada em História pela Universidade Estadual de Ponta Grossa e Especialista em História das Revoluções e dos Movimentos Sociais pela Universidade Estadual de Maringá. E-mail: audiboutin@hotmail.com.
} 


\begin{abstract}
This article is a result of research from the Núcleo de Estudos e Pesquisa: Estado, Políticas Públicas e Práticas Sociais - (NUEPPS). It aims to present an analysis of the conceptions of Education, Unitary School, and Disinterested School in the set of gramscianos articles available in the IGSBrazil. It also presents to what extent the conception of education found in the evaluated articles relates to the theoretical reflections of Gramsci. The methodology contains a) a survey of the articles dealing with the education category in the IGS - Brazil; b) identification of the themes that stands out in the education category; c) selection of the most significant fragments; and d) analysis of these fragments in the light of the Gramscian reference. It is concluded that the categories of Unitary School and Disinterested School are highlighted in the articles that aim at education from the perspective of gramscianos and in postgraduate teaching, in accordance with the set of works by Antônio Gramsci.
\end{abstract}

Keywords: Bibliographical map of Gramsci in Brazil; Education conception; Unitary and disinterested school conception.

Recebido em: 15/10/2019. Aceito em: 03/06/2020.

\title{
Introdução
}

O presente artigo é fruto de um conjunto de reflexões sistematizadas a partir da experiência dos pesquisadores/autores no NEPPS², o qual é constituído de profissionais de diversas áreas, especificamente na pesquisa, originária deste artigo: educação, direito e serviço social que possuem um objeto de pesquisa em comum, portanto interdisciplinar: a obra gramsciana no Brasil.

Trata-se de uma pesquisa bibliográfica, desenvolvida no decorrer do segundo semestre do ano de 2017, tomando como parâmetro de pesquisa o Mapa da Bibliografia do Gramsci no Brasil, do "International Gramsci Society do Brazil" - IGS-BR. Indagou-se, inicialmente, quais as principais categorias teóricas gramscianas presentes nas produções de conhecimento citadas no respectivo mapa. Diante de tais questionamentos, a pesquisa teve por objetivo analisar as incidências de diferentes categorias teóricas Gramscianas presentes no respectivo mapa bibliográfico, do IGS-BR. Os resultados da investigação buscam contribuir para a visibilidade dos estudos na perspectiva gramsciana no campo das Ciências Sociais Aplicadas no país.

Considerando a necessidade da acessibilidade ao inteiro teor da produção para a definição do universo a ser pesquisado e ainda buscando eleger um conjunto de produções que fosse homogêneo, em seu formato, definiu-se como universo da pesquisa o conjunto de artigos, devidamente citados no mapa e disponíveis on-line, ao que se chegou a um total de 89 produções. Nestas foram identificadas as principais categorias trabalhadas pelos artigos, respectivamente nesta sequência quantitativa de incidência: Hegemonia/21 artigos; Educação:14; Estado e Sociedade Civil:14;

\footnotetext{
2 O Núcleo de Estudos e Pesquisa: Estado, Políticas Públicas e Práticas Sociais (NEPPS) vinculado ao Programa de PósGraduação em Ciências Sociais Aplicadas, da Universidade Estadual de Ponta Grossa - UEPG - Paraná - Brasil, desenvolve pesquisas relacionadas as temáticas acima referidas, desde 2010.
} 
História e Política:12; Intelectuais:8; Filosofia da Práxis:5; Classes e grupos subalternos:5; Cultura :3; Vontade Coletiva:2; Partido Político:1; Ideologia:1; Revolução Passiva:1; Trabalho, Taylorismo, Fordismo:1;Outros:1.

Decorreram deste levantamento quantitativo a produção de artigos que sistematizaram a primeira etapa da pesquisa, ou seja, todo o processo desenvolvido para se chegar a um panorama geral da produção / artigos e suas especificidades. Também artigos sobre cada uma das categorias identificadas como resultado da pesquisa realizada. Dentre eles, o presente artigo que trata em específico da categoria Educação, sistematizada em quatorze artigos ${ }^{3}$ do universo de pesquisa (89 artigos).

Como parte do processo de pesquisa realizado, o objetivo deste artigo é traçar uma análise das concepções de Educação e de Escola Unitária e Desinteressada tratadas nos artigos em análise. Também é objetivo identificar em que medida essas concepções se alinham ou se distanciam das concepções originárias de Gramsci.

O procedimento metodológico adotada para a coleta e análise de dados na amostra de pesquisa foi a pesquisa bibliográfica. No transcorrer do artigo, serão utilizados fragmentos dos textos pesquisados, identificando seus respectivos autores, e compondo um texto analítico do conteúdo deles.

Estruturalmente o artigo está organizado em duas partes: A concepção de educação em Gramsci e a concepção de escola unitária e de escola desinteressada nos artigos analisados.

A análise da categoria educação, tem papel fundamental nos escritos gramscianos, sobretudo na influência que ela exerce, na elevação do grupo social e na compreensão política da situação vivenciada. A elevação política de um grupo social implica, segundo Gramsci (1995) trabalhar na construção de uma nova filosofia, ou seja, definir sua própria filosofia e combater o senso comum, visando à formação de uma nova concepção do mundo, mais unitária e autônoma, em todos os aspectos da existência e ser um bem coletivo.

A escola pensada por Gramsci deriva da teoria marxista e expande seus horizontes em sentidos mais amplos em relação a cultura e educação. A escola unitária e a escola desinteressada são as nomenclaturas utilizadas pelo autor para explicar as mudanças de paradigmas hegemônicos em relação a educação.

\section{A Concepção de Educação em Gramsci}

Os achados de pesquisa, na amostra em questão, aqui apresentados, indicam que a educação na concepção gramsciana assume uma dupla perspectiva: de um lado ela é utilizada para a conservação da hegemonia dominante no sistema de classes, e de outro, enquanto uma possibilidade de construção da hegemonia subalterna, ou seja, assume uma dimensão política cujo fim é iluminar a práxis transformadora do real.

Esta última perspectiva pode ser evidenciada se recorrermos aos escritos gramscianos. Neles é possível evidenciar a dimensão política que a educação pode assumir em um sistema de classes, uma vez que Gramsci não apenas indicou as potencialidades da educação formal, institucionalizada no modelo escolar, para a superação das desigualdades sociais, mas também considerou que os canais alternativos de formação política, os quais em nosso entendimento são

\footnotetext{
${ }^{3}$ A lista com os quatorze artigos que tratam da categoria "educação" na concepção gramsciana, encontra-se ao final deste artigo.
} 
meios de educação não formal, podem efetivamente contribuir para a construção da hegemonia subalterna. (GRAMSCI, 2004); (GRAMSCI, 2016).

No entanto, para além de uma visão romantizada em que a educação é colocada como a solução para as mazelas sociais, Gramsci não deixou de considerar, que a educação organizada no modo de produção capitalista, tende a reproduzir os interesses da classe que detém a primazia no terreno social, a classe dominante, e desse modo, ela é legitimadora da dualidade estrutural da sociedade.

Esta reflexão se apresenta e permeia as análises dos 14 artigos que discorrem sobre educação na perspectiva gramsciana, conforme indica um dos fragmentos selecionados:

O autor vê a escola numa perspectiva ampla e dinâmica, relacionando-a com o universo sócio cultural da classe dominante. Registra-se em seus estudos que a hegemonia dessa classe não desenvolve um tipo de ensino democrático pelo fato de a mesma estar voltada apenas para o seu próprio interesse. [...]. (RODRIGUES, 1987, p. 134, grifos nossos.)

De acordo com a perspectiva em tela, é possível indicar que Gramsci não exclui de suas análises as limitações atreladas ao sistema de ensino formal, sob o domínio da lógica burguesa. O entendimento gramsciano sobre a educação, portanto, considera que a hegemonia dominante incide também sobre o ensino. A classe que detém o controle no campo econômico, político e social, organiza o ensino de modo a contribuir para a conservação das relações sociais, para a conformação e conformismo. Desse modo, para Gramsci, a educação é utilizada enquanto estratégia que molda o homem e as suas ações. (LIGUORI; VOZA, 2017).

É nesse sentido que a educação oferecida aos subalternos ${ }^{4}$ tem como fim a satisfação dos "interesses práticos imediatos" (GRAMSCI, 2001, p. 49) e sendo assim, ensino é organizado de modo a priorizar, a formação técnica, fragmentada e parcializada, voltada para a reprodução de "uma determinada função social, dirigente ou instrumental (p. 49)".

Para esta classe, o ensino é estruturado de modo a contribuir para uma formação voltada para o trabalho, desse modo, a formação é técnica, comprometida com a realização de uma determinada função social, a de dirigido. De maneira oposta, a educação das classes dominantes é estruturada de modo a priorizar a formação humanística, comprometida com a manutenção do status de dirigente nos aspectos sociais, político e econômico. (GRAMSCI, 2001).

Os limites apresentados na educação a partir da perspectiva gramsciana, portanto, podem ser identificados a partir da divisão estrutural da sociedade, a qual também incide na fragmentação do ensino. Essa perspectiva se constitui enquanto norteadora, dos artigos analisados, conforme evidencia o fragmento selecionado:

[...] a crítica gramsciana ao caráter classista da escola burguesa se dirige mais especificamente ao seu aspecto discriminatório, segregador, oligárquico, [...]

\footnotetext{
${ }^{4}$ Segundo YAZBEK (1993), a categoria subalterno pertence ao legado gramsciano e a "subalternidade diz respeito à ausência 'de poder de mando, de poder de decisão, de poder de criação e de direção'(Almeida) (...) faz parte do mundo dos dominados, dos submetidos à exploração e à exclusão social, econômica e política (...) predominam os interesses dos que detém o poder econômico e de decisão política (...) Historicamente, os subalternizados vêm construindo seus projetos com bases em interesses que não são seus, mas que são inculcados como seus. Experienciam a dominação e a aceitam, uma vez que as classes dominantes, para assegurar sua hegemonia ou dominação, criam formas de difundir e reproduzir seus interesses como aspirações legítimas de toda sociedade (...) a subalternidade vem sendo introjetada ao longo de nossa história, e a experiência política predominante na sociedade brasileira é a dominação, apesar dos 'ricos momentos sóciopolíticos de lutas entre dominados e dominantes'. (Almeida)" (YAZBEK,1993, p. 18)
} 
e que se manifesta fundamentalmente no fato de não proporcionar ás camadas populares a apropriação do saber elaborado (as ciências, as humanidades e as artes) conservando-se como privilégio das elites. (SILVEIRA, 2015, p. 563, grifos nossos).

Os artigos analisados, portanto, se alinham a perspectiva gramsciana de que a educação no sistema de classes tende a reproduzir as desigualdades presentes na sociedade. No entanto, o reconhecimento do comprometimento do ensino em relação a perpetuação das diferenças sociais, não cerceou a possibilidade de Gramsci (2001) considerá-lo enquanto um meio para a construção da hegemonia subalterna.

Para Gramsci, a educação ao passo que é uma estratégia da classe dominante para se manter no controle do processo social, pode se converter em um instrumento pelo qual os subalternos podem organizar sua cultura, forjar uma ideologia no terreno social, fomentando uma reforma intelectual e moral necessária para a construção de um movimento contra- hegemônico. (LIGUORI; VOZA, 2017).

De acordo com Liguori e Voza (2017) a educação em Gramsci assume o objetivo de "conduzir os simples para uma concepção superior de vida" (p. 234). A educação, nesse entendimento, descontruir as ideologias e o senso comum que contribuem para a inatividade e passividade dos subalternos frente as relações de submissão a que estão atrelados, instrumentalizando-os para a ação transformadora do real, ou seja, para um processo de emancipação, de construção da hegemonia subalterna.

Essa reflexão que coloca em relevo a dimensão política da educação na concepção gramsciana também se apresenta nos artigos que analisamos, conforme indica o trecho selecionado para a análise:

Assim a posição gramsciana a respeito da relação educação e sociedade permite superar tanto o dualismo característico tanto da perspectiva liberal, quanto do determinismo e o imobilismo de algumas teorias, reprodutivistas, ajudando a identificar as reais possibilidades de intervenção social por meio da ação educativa escolar com vistas a construção de uma nova hegemonia. (SILVEIRA, 2015, p. 572, grifos nossos)

Desse modo, no fragmento selecionado, se evidencia a articulação entre os limites e as possibilidades emancipatórias latentes na ação educativa escolar. Em outra passagem selecionada para a análise também podemos evidenciar a interpretação do autor sobre os limites e possibilidades da educação na concepção gramsciana, conforme expõe:

Por considerar a escola uma das organizações da sociedade civil responsáveis pela elaboração e divulgação da ideologia, Gramsci lhe conferirá especial atenção [...]. Nesse sentido, percebe nela tanto a possibilidade de reiteração da concepção de mundo das classes dominantes, quanto a de atuação no sentido de contribuir para a reforma intelectual e moral da massa trabalhadora, tendo por horizonte a superação da sociedade capitalista. Na perspectiva da luta hegemônica, a escola caberia promover a educação das massas populares com o objetivo de libertá-las da visão folclórica de mundo e dos mitos, tendo em vista a construção de uma consciência unitária. (FERRETTI, 2009, p. 120, grifos nossos). 
Assim sendo, a educação em Gramsci, na interpretação de Ferreti (2009) possui uma dupla possibilidade: validar ou abolir as injustiças e as desigualdades presentes na sociedade, sendo que, essa última está atrelada a necessidade da elevação cultural dos subalternos por meio da construção de uma consciência pautada no coletivo.

A possibilidade da educação contribuir para a elevação cultural dos subalternos e para a criação de "uma nova cultura" (GRAMSCI, 1978, p. 13), pautada no coletivo e na necessidade de instrumentalizar os subalternos para a ação transformadora do real, para a leitura dos limites e condicionantes que permeiam a materialidade constituem os fundamentos das reflexões de Gramsci sobre a educação.

Gramsci (2004) além de reconhecer a necessidade da construção da cultura subalterna, também indicou que isso não dá de forma imediata. Para ele "essa consciência se forma [...] através da reflexão inteligente, primeiro de alguns e depois de toda uma classe”. (p. 59) e avança, expondo que o movimento de transformação social é precedido "por um intenso trabalho de crítica, de penetração cultural, de impregnação de ideias de um agregado de homens” (p. 59).

A elevação intelectual das classes subalternas para Gramsci, se instituiria em face a apropriação subalterna dos conhecimentos historicamente acumulados pela humanidade, nos quais embora incidam ideologias de conservação societária, também contribuem para o desenvolvimento de uma consciência amparada na crítica e na leitura das contradições que permeiam essa base estrutural e superestrutural da sociedade.

O pressuposto de que a elevação cultural propiciada, por meio da educação, poderia instrumentalizar os subalternos para a ação transformadora do real, também é evidenciado nas reflexões dos autores que analisamos, conforme indicam as citações:

A educação na concepção gramsciana, portanto, só poderia estar voltada para a transformação da concepção de mundo dos sujeitos, através de uma filosofia capaz de abalar as fortificações, de transformar as mentalidades e de permitir a elevação cultural, ou seja, a filosofia da práxis. (BAPTISTA, 2010, p.182)

A articulação entre educação, elevação cultural e práxis política é também destacada no seguinte fragmento:

[...] a obra e a práxis política de Gramsci caracterizam-se pelo "otimismo da vontade e pessimismo da razão", para utilizar uma sua celebre expressão. Isto é a dúvida metódica da razão não mata o engajamento da vontade de alterar as relações sociais tendo a escola como um instrumento fundamental para a emancipação humana, pois a educação e a cultura são o substrato para o cultivo de um novo consenso em favor de valores como a solidariedade e igualdade construção de um mundo mais justo e fraterno. (NOSELLA; AZEVEDO, 2012, p. 28, grifos nossos).

Na citação explicita-se que a educação é uma prática facilitadora de uma reforma intelectual, necessária para a formação de um consenso social em relação a construção da hegemonia subalterna.

A articulação entre educação, formação de um consenso e práxis política, aqui entendida como ação voltada para a construção da hegemonia subalterna, estão presentes nas reflexões de Gramsci (2001). No entanto, é importante destacar que, para Gramsci, a construção da hegemonia subalterna, pressupõe a existência de uma ideologia que sustente as ações e a práxis comprometida com uma revolução social. 
É nesse sentido que, de acordo com Liguori e Voza (2017, p. 399) a ideologia em Gramsci "não é em si negativa" e sendo assim, a relação entre a educação e a formação de uma ideologia que de sustentação a formação dos sujeitos enquanto participantes do processo social, ou seja, que instaure uma reforma intelectual, necessária para orientar a classe subalterna à processos emancipatórios.

Os artigos que se propuseram a tecer reflexões sobre a educação na perspectiva gramsciana, não deixaram de considerar a importância que a ideologia assume no processo de reforma intelectual dos subalternos, conforme indica o trecho selecionado para as análises:

[...] esta relação se define na relação entre reforma intelectual (formação do homem novo, partícipe ativo na construção de um novo modelo de sociedade, a socialista) e reforma econômica (revolução proletária como forma de inspiração). Nesse sentido, vale salientar a importância atribuída por Gramsci à ideologia, enquanto conceito central de uma reforma ou luta cultural, de uma hegemonia política, no seio da sociedade capitalista, imprescindível a uma guerra de posição. (BAPTISTA, 2010, p. 188, grifos nossos)

Se em Gramsci, conforme apontam Liguori e Voza (2017, p. 400) “a luta pela hegemonia é luta de ideologias" e estas não se apresentam apenas nas instituições da sociedade civil, mas também incidem nos aspectos sociais, políticos e econômico, portanto, partem de uma base material (estrutura) que molda e determina as superestruturas. Nesse sentido, a educação para Gramsci, enquanto constituinte das superestruturas, poderia preparar um terreno ideológico que desse sustentação e forjasse um movimento contra hegemônico.

A educação na perspectiva em tela, não apenas contribui para a solidificação de uma ideologia pautada em projetos de transformações societárias, como também contribui para a formação de uma nova classe dirigente. Essa relação entre ideologia, educação e práxis política, também se apresentou de maneira bastante enfática nos artigos que utilizaram Gramsci para discorrer sobre educação e ensino, conforme indica o fragmento em destaque:

Gramsci considerava de suma importância educar um grupo de dirigente da classe operária nas condições de refluxo e de terror em que se vivia, pois, esse grupo deveria estar preparado para dirigir o processo revolucionário. Tal grupo dirigente era também importante para administrar o Estado proletário e para educar massas crescentes de trabalhadores no sentido da Emancipação, sem que essas voltassem a ficar sob a influência das velhas ideológicas. Assim, a tarefa de preparação para dirigir a revolução e administrar o Estado proletário deveria ser enfrentada desde já. (DEL ROIO, 2006, p. 323)

A educação, nessa perspectiva se converte em um meio pelo qual a classe subalterna pode tanto superar a sua condição de submissão como podem também contribuir para a preparação do terreno ideológico e cultural para que possam finalmente assumir o controle do processo social.

A formação desse novo homem, cuja ação esteja atrelada com a práxis política se materializaria por meio de uma educação desinteressada e de uma escola unitária. Tais conceitos, tão importantes, para compreender como a educação pode se efetivar enquanto uma possibilidade de transformação social, também permearam as reflexões dos artigos que analisamos, conforme iremos apresentar nos tópicos que seguem.

Nesse sentido, dois elementos são compreendidos nas discussões em Gramsci sobre a categoria educação: escola unitária e escola desinteressada, as quais serão retrataras a seguir. 


\section{A Concepção de Escola Unitária e de Escola Desinteressada}

As reflexões acerca da temática escola desinteressada e escola unitária, nos artigos analisados aparecem sempre na relação com o conceito/categoria de hegemonia. Destes, apenas oito deles utilizam os dois elementos (escola unitária e escola desinteressada), os quais serão apresentados aqui, articulando com o pensamento gramsciano.

É importante ressaltar que em todos os artigos em que se apresentam as subcategorias em questão, todas convergem com a matriz epistemológica de Gramsci. A principal fonte de referências para as articulações em relação ao pensamento gramsciano e as discussões de escola unitária e escola desinteressada são os «Cadernos do cárcere» (principalmente o volume 2) e «Os intelectuais e a organização da cultura».

Os artigos analisados apresentam fragmentos significativos que ratificam esta visão de educação apresentadas pela teoria gramsciana. Ao estabelecer relações entre os textos em questão, evidencia-se uma clareza nos sentidos e significados da escola unitária e escola desinteressada.

Ao se reportar a teoria gramsciana, é preciso compreender que seu pensamento deriva do marxismo e por isso, suas reflexões partem dele. Marx e Engels pensam a escola como uma ferramenta de transformação social que deve desarticular um bloco histórico e desencadear ações políticos-culturais, com objetivo de articular um novo bloco histórico, conforme afirma Ferretti (2009).

Gramsci reconhece a necessidade de uma mudança na perspectiva educacional que deve ser articulada pelo intelectual orgânico da classe trabalhadora. Ferreti (2009) ressalta que a mudança que o pensador sardo propõe se dá no sentido de superar a "escola clássica ${ }^{5}$ ", reflexo de uma crise mais ampla de toda a sociedade. Para o enfrentamento da crise, o autor propõe que:

uma escola única inicial de cultura geral, humanista, formativa, que equilibre equanimemente o desenvolvimento da capacidade de trabalhar manualmente (tecnicamente, industrialmente) e o desenvolvimento das capacidades de desenvolvimento intelectual. Deste tipo de escola única, através de repetidas experiências de orientação profissional, passar-se-á a uma das escolas especializadas ou ao trabalho produtivo. [...] A escola unitária ou de formação humanista [...] deveria propor a tarefa de inserir os jovens na atividade social, depois de tê-los levado a um certo grau de maturidade e capacidade, à criação intelectual e prática. (GRAMSCI, 1979, p. 118 e 121)

O caráter unitário, neste sentido, decorre de um princípio formativo que estrutura a escola e a disciplina como uma escola criadora e ativa. No sentido mais restrito da palavra, escola unitária caminha lado a lado com os conceitos de trabalho e de educação, em que as relações escolanovistas ganham força em contraposição a postura jesuítica de educação. A escola ativa, deve superar a instrução proposta pela escola tradicional e criar na consciência da criança de uma escola transformadora da realidade e das relações sociais.

Ainda nesta perspectiva, Gramsci (1979, p. 124) procura romper com o caráter classista da escola e propõe dois níveis na escola unitária: no primeiro, na "escola ativa" (não de tipo libertária) que busca-se disciplinar, atingir uma "coletivização" do tipo social; no segundo, na escola criadora, busca-se "criar os valores fundamentais do 'humanismo', a autodisciplina intelectual

\footnotetext{
${ }^{5}$ A divisão fundamental da escola em clássica e profissional era um esquema racional: a escola profissional para as classes instrumentais, ao passo que a clássica para as classes dominantes e para os intelectuais. (MONASTA, 2010, p. 98)
} 
e a autonomia moral" necessários a uma posterior preparação de caráter científico (estudo universitário) ou de caráter imediatamente prático-produtivo (indústria, burocracia, organização de trocas, etc.)

A escola unitária propõe o início de novas relações entre trabalho intelectual e trabalho industrial não apenas na escola, mas em toda a vida social (NOSELLA; AZEVEDO, 2012). Desta forma, o princípio unitário, "refletir-se-á em todos os organismos de cultura, transformando-os em emprestando-lhes um novo conteúdo" (GRAMSCI, 2012, p. 47). Ela se articula com um "centro homogêneo de cultura' que precisa levar em consideração duas ações: concepção de mundo e o programa escolar" (SEMERARO, 2011).

Desta forma, a escola é pensada como única, elementar e média até o momento da preparação profissional e deve formar o jovem como pessoa “[...] capaz de pensar, de estudar, de dirigir ou de controlar quem dirige”. (GRAMSCI, 2001, p. 46). Para Gramsci:

é o dirigente que a escola unitária deve formar, como "[...] escola única geral de cultura geral, humanista, formativa", em que haja equilíbrio entre a formação da "[...] capacidade de trabalhar manualmente (tecnicamente, industrialmente) e o desenvolvimento das capacidades de trabalho intelectual". (GRAMSCI, 2001, p.31)

Para superar a dicotomia de escola interessada e desinteressada é preciso olhar a educação pela perspectiva unitária, que vai das "relações intersubjetivas até a complexidade das relações políticas 'hegemônicas' que se travam no âmbito nacional e internacional” (SEMERARO, 2011, p. 144).

Del Roio (2006, p. 312) complementa essa afirmação, explicando que "o desafio era o de pensar a escola socialista unitária, que articulasse o ensino técnico-científico ao saber humanista.

Sememaro (2012) ainda lembra que em uma sociedade desigual e fragmentada, a 'escola unitária' apresenta uma perspectiva revolucionária, que rompe não apenas com a concepção desigual e dualista, mas também com a visão liberal e individualista.

O grande objetivo de se pensar e incorporar a escola unitária é recompor a unidade do ser humano, não mais como dominação, mas como "poder de atração" (GRAMSCI, 2012). Os novos sujeitos hegemônicos, formados a partir da escola unitária, serão formados por experiências vivenciadas na coerência do próprio agir e pela consistência de um projeto de sociedade em condições efetivas de universalizar direitos e democratizar o poder. (SEMERARO, 2012, p. 149).

A escola unitária pode contribuir para a discussão sobre a organização da cultura. Sobretudo na sociedade industrial, que colocou a escola humanista em crise, é importante que "da técnicatrabalho alcança a técnica-ciência e a concepção histórica humanista, sem a qual permanece ‘especialista' e não se torna 'dirigente' (especialista + político)”. (GRAMSCI, 1977, p. 1551)

Rompendo com a educação posta pela sociedade industrial, Nosella e Azevedo (2012) reforçam que a intelectualidade e os partidos políticos passam, a tratar a escola e a educação como destacados objetos de elaboração filosófica e política, porque, como podemos notar, a escola está cada vez mais aberta não apenas para os jovens das classes privilegiadas, mas também para àqueles que advém de classes subalternas.

No entanto, Nosella e Azevedo (2012, p. 26-27) lembram que a busca pela escola unitária:

[...] não significou o fim das diferenças de classe social. A estrutura dualista na sociedade ainda manifesta-se horizontalmente, distinguindo e separando aqueles que continuam os estudos em busca da ciência daqueles que são obri- 
gados a deixar os bancos escolares pelas bancadas de trabalho; verticalmente, separa os que estudam em escolas "desinteressadas", isto é, de rigor científico e de ampla cultura geral que os habilitam para os cargos de direção da sociedade, dos que frequentam as escolas "interessadas" que os habitam tão somente para a execução do trabalho e a aplicação da técnica (escolas profissionalizantes).

Gramsci apresenta outro elemento nas discussões, a escola interessada e desinteressada do trabalho. Ao questionar a dualidade do sistema escolar, explica os dois tipos de escola em sua concepção: a desinteressada do trabalho, com um programa humanista, de cultura universal, a quem não precise se submeter precocemente ao mercado de trabalho; e a escola interessada do trabalho, profissionalizante, com um pragmático e pobre currículo, para as grandes massas, capaz de formar jovens para o imediatismo do mercado, sem preocupações com os valores universais. (NOSELA E AZEVEDO, 2012).

Del Roio (2006) lembra que a relação entre a escola e a experiência de vida ainda se diferencia conforme a classe social do estudante. Para os jovens da burguesia, por serem da classe dominante, a escola serve para treiná-los, para adequá-los para se portarem e se verem como dominantes. A escola da classe burguesa, que na Itália se expressava na sequência ginásio-liceu-universidade, deve agir para formar a classe dirigente e seu eventual fracasso é o fracasso dessa classe. Além disso, "[...] para a classe operária, o Estado burguês organizou um tipo de escola: a escola popular e a escola profissional, voltadas a manter a divisão de classe, a fazer com que o filho de operário seja também ele um operário" (DEL ROIO, 2006, p. 60)

Gramsci insiste na escola unitária e desinteressada do trabalho para todos. Desinteressada, num aspecto cultural amplo, que faça os sujeitos compreenderem as raízes históricas do trabalho e suas potencialidades técnicas. Nesse sentido, "não é possível pensar numa escola de curta duração, precocemente profissionalizante que objetiva treinar um operador de máquinas, preciso e submisso. (NOSELA E AZEVEDO, 2012, p. 27)

Nas discussões da escola unitária e desinteressada, a práxis exerce um papel fundante como elemento da emancipação humana. Baptista (2010) lembra que é através da prática social (práxis), de uma nova concepção do mundo mais unitária e autônoma em todos os aspectos de sua existência.

O professor nesse contexto, exerce um papel significativo na busca pela emancipação humana. É a prática pedagógica e a aprendizagem significativa, que consegue fazer uma leitura real da escola, percebendo os aspectos da educação fragmentada e contraditória. Somente a partir desta leitura, mais crítica que o professor poderá elaborar de forma unitária sua compreensão acerca da relação desenvolvimento e aprendizagem, do processo educativo, enfim, da relação educação e sociedade. (BAPTISTA, 2010)

Segundo Ferreti (2009), discutir sobre a proposta de uma escola unificada e desinteressada, não significa o mesmo que educação integral, objeto do enfoque socialista. Mas, a perspectiva de que os trabalhadores viam no sistema escolar unificado uma medida de democratização do acesso à educação e o reivindicavam.

A escola unitária que Gramsci propõe não se limita apenas a produzir profissionais e a modernizar o país, mas deve estar organizada para uma formação ampla e integral que prepare os jovens a tornar-se "dirigentes" da própria sociedade. (SEMERARO, 2011). Mais que preparar gente ativa, é preciso formar sujeitos autônomos e criativos, capazes de ser especializados e políticos. 
Semeraro complementa que "Gramsci denunciava a escola "desinteressada" como "um privilégio de quem pode pagar" enquanto ao operário absorvido pelo trabalho extenuante da fábrica eram negadas as condições de estudar seriamente" (2006, p. 146)

Ao se opor à concepção elitista, dualista e autoritária de escola, Gramsci se defronta também o com as propostas provenientes das teorias da escola ativa e progressista que se apresentavam com o propósito de superar o dualismo e a visão tradicional de mundo. Para ele, embora essa pedagogia moderna apresente novidades, quando se enfatiza os "interesses" do aluno, outras relações são suprimidas, e os afastam de problemas mais amplos da sociedade como a política e os conflitos de classes. Gramsci ainda afirma que essa concepção acentua a liberdade individual e a educação não diretiva leva a falta de direção (SEMERARO, 2006).

Nesse sentido, Semeraro (2006) reforça que a escola progressista (ativa) e escola unitária e desinteressada se opõe, pois a primeira está voltada a desenvolver a autonomia e as capacidades práticas dos indivíduos e segunda trata-se de uma educação que emana do mundo do trabalho como forma de superação das divisões sociais e estabelecer uma hegemonia de relações efetivamente democráticas.

A educação unitária e desinteressada, portanto, para Gramsci não acontece apenas na sala de aula ou nas relações escolares, mas no amplo conhecimento de mundo, sobretudo no mercado de trabalho, com os conselhos de fábrica, como o lugar fundamental e permanente de uma educação concreta de autoconsciência coletiva. Dessa forma, Semeraro (2006, p. 151) ressalta que "é na escola de trabalho que se aprendem não apenas técnicas para produzir objetos e movimentar as máquinas, mas principalmente a complexidade que estrutura o sistema social e as contradições existentes entre grupos de poder e a massa popular".

Em contraposição a reforma de Gentile (1921) que acentuava e "explicitava a dualidade do sistema educativo italiano, ao reservar um ramo clássico-humanista para as classes dirigentes" e restringia o acesso à educação voltada para as massas, apenas como a especialização precoce da força de trabalho. (DEL ROIO, 2006, 323), Gramsci enaltece a disciplina do estudo e o rigor nos métodos pedagógicos que, combatem a arbitrariedade e o autoritarismo como base fundamental para a formação dos professores.

Em Gramsci, não apenas a política é chamada a assumir um caráter pedagógico, mas também a educação deixa de ser entendida como processo pessoal, individual, intimista ou limitado aos muros da escola e passa a ser entendida como um espaço de construção de uma personalidade social e de conquista de um novo conceito de hegemonia. (SEMERARO, 2006)

Desta forma, “[...] a crítica de Gramsci à organização da educação na sociedade capitalista se dá em relação à divisão da escola clássica e escola profissional”, que vislumbra um racionalismo exacerbado, onde a escola profissional destina-se aos filhos dos trabalhadores e a escola clássica aos filhos das classes dominantes intelectuais. (DIAS, 1997, p.35)

\section{Considerações Finais}

Este artigo teve como objetivo discorrer sobre a concepção de educação abordada nos artigos que utilizam o pensamento de Gramsci como referencial teórico. Constatou-se que os 14 artigos, localizados no Mapa da Bibliografia do Gramsci no Brasil, do "International Gramsci Society do Brazil", que tratam da educação, as temáticas que se destacaram dizem respeito a escola unitária e a educação desinteressada. 
Através da pesquisa bibliográfica foi possível identificar que a concepção de educação abordada nos artigos analisados se alinham ao pensamento de Gramsci na medida em que não se limitam a crítica em relação a função assumida pela educação na sociedade de classes, mas também elevam o potencial da educação enquanto uma prática que efetivamente pode contribuir para a elevação cultural dos subalternos e desse modo orientá-los para uma prática alinhada à transformação do real.

Fica claro como elemento fundamental no pensamento gramsciano ao analisar os artigos, que a escola tem dupla função: legitimar a ideologia dominante e/ou promover a elevação cultural da classe subalterna.

Em relação a escola unitária e a escola desinteressada destaca-se o papel fundamental da educação para promover a elevação da cultura e estabelecer uma contra hegemonia ao sistema escolar pensado para o capitalismo. A escola deverá ser unitária, ou seja, única para toda a população, pois a educação, é um elemento fundamental para construir uma nova ordem social.

Além disso a escola deve ser desinteressada do trabalho, levando em consideração a formação integral da pessoa, nos aspectos culturais e sociais e de compreensão crítica do mundo do trabalho e não apenas aprender as funções pré-estabelecidas para manter a ordem social dominante.

\section{Referências}

BAPTISTA, M das G. de A. Práxis e educação em Gramsci. Filosofia e Educação (Online). Revista Digital do Paideia, Ribeirão Preto, v. 2, n. 1, p. 181-2013, abr./set. 2010.

DEL RIO, M. Gramsci e a educação do educador. Cad. Cedes, Campinas, v. 26, n. 70, p. 311- 328, set./dez. 2006.

FERRETI, C. J. O pensamento educacional em Marx e Gramsci e a concepção de politécnica. Trab. Educ e Saúde, Rio de Janeiro, v. 07, suplemento, p. 105-128, 2009.

GRAMSCI, A. Cadernos do cárcere, vol. 2. Rio de Janeiro: Civilização Brasileira, 2001.

GRAMSCI, A. Cadernos do cárcere, vol. 3. Rio de Janeiro: Civilização Brasileira, 2016.

GRAMSCI, A. Concepção dialética da história. Rio de Janeiro: Civilização Brasileira, 1978.

GRAMSCI, A. Concepção dialética da História. Rio de Janeiro: Civilização brasileira, 1995.

GRAMSCI, A. Escritos políticos, vol. 1. Rio de Janeiro: Civilização brasileira, 2004.

GRAMSCI, A. Os intelectuais e a organização da cultura. Rio de Janeiro: Civilização brasileira, 1979.

LIGUORI, G.; VOZA, P. Dicionário Gramsciano. São Paulo: Boitempo, 2017.

MANACORDA, M. A. O princípio educativo em Gramsci: americanismo e conformismo. Campinas: Alínea, 2008.

MONASTA, A. Antônio Gramsci. Recife: Massangana, 2010.

NOSELlA, P.; AZEVEDO, M. L. N de. A educação em Gramsci. Rev. Teoria e Prática da Educação, Maringá, v. 15, n. 02, p. 25-33, maio./ago. 2012.

RODRIGUES, M. R. N. A questão da educação no pensamento de Gramsci. Cadernos de Pesquisa, São Luís, v. 03, n. 02, p. 129-135, jul./dez. 1987. 
SILVEIRA, R. J. T. Escola e classe social de uma perspectiva gramsciana: a sala de aula, o intelectual e os simples. ETD - Educ. Tem. Digit., Campinas, v. 17, n. 03, p. 558- 575, set./dez, 2015.

YASBEK, M. C. Classes Subalternas e Assistência Social. São Paulo: Cortez. 1993.

\section{Artigos que compuseram o universo da pesquisa}

BAPTISTA, M das G. de A. Práxis e educação em Gramsci. Filosofia e Educação (Online). Revista Digital do Paideia, Ribeirão Preto, v. 2, n. 1, p. 181- 2013, abr./set. 2010.

DIAS, G. A educação escolar e a construção da contra hegemonia burguesa. Educar, Curitiba, n.13, p. 35-44, abr./set. 1997.

DEL RIO, M. Gramsci e a educação do educador. Cad. Cedes, Campinas, v. 26, n. 70, p. 311- 328, set./dez. 2006.

DORE, R. Afinal o que significa o princípio educativo em Gramsci? Cad. Cedes, Campinas, v. 34, n. 94, p. 297-316, set./dez. 2014.

DURANDE, J. C. G. Educação e hegemonia de classe: as funções ideológicas da escola. Revista Administração de Empresas, Rio de Janeiro, v. 20, n. 02, p. 70-81, abr./jun. 1980.

FERRETI, C. J. O pensamento educacional em Marx e Gramsci e a concepção de politecnia. Trab. Educ e Saúde, Rio de Janeiro, v. 07, suplemento, p. 105-128, 2009.

MAGRONE, E. Gramsci e a educação: a renovação de uma agenda esquecida. Cad. Cedes, Campinas, v. 26, n. 70, p. 353-372, set./dez, 2006.

NOSELLA, P. Ensino Médio unitário ou multiforme? Revista Brasileira de Educação, Rio de Janeiro, v. 20, n. 60, p. 122- 142, jan./mar. 2015.

NOSELLA, P. Gramsci e os educadores brasileiros. Revista da FEBBA, Salvador, n. 10, p. 09- 24, jul./dez, 1998.

NOSELlA, P.; AZEVEDO, M. L. N de. A educação em Gramsci. Rev. Teoria e Prática da Educação, Maringá, v. 15, n. 02, p. 25-33, maio./ago. 2012.

RODRIGUES, M. R. N. A política educacional e a instituição escolar no pensamento da ideologia pós liberal: uma análise. Cadernos de Pesquisa, São Luís, v. 05, n. 02, p. 123-143, jul./dez. 1989.

RODRIGUES, M. R. N. A questão da educação no pensamento de Gramsci. Cadernos de Pesquisa, São Luís, v. 03, n. 02, p. 129-135, jul./dez. 1987.

SEMERARO, G. Gramsci educador de relações hegemônicas. Rev. Educação Cultura e Sociedade, São Luís, v. 01, n. 02, p. 143-156, fev./jun. 2011.

SILVEIRA, R. J. T. Escola e classe social de uma perspectiva gramsciana: a sala de aula, o intelectual e os simples. ETD - Educ. Tem. Digit., Campinas, v. 17, n. 03, p. 558- 575, set./dez, 2015. 